University of Nebraska - Lincoln

DigitalCommons@University of Nebraska - Lincoln

\title{
An In Vitro Comparative Study on the Reactivation of Nerve Agent- Inhibited Guinea Pig and Human Acetylcholinesterases by Oximes
}

Chunyuan Luo

Min Tong

Nageswararao Chilukuri

Karen Brecht

Donald M. Maxwell

See next page for additional authors

Follow this and additional works at: https://digitalcommons.unl.edu/usarmyresearch

Part of the Operations Research, Systems Engineering and Industrial Engineering Commons

Luo, Chunyuan; Tong, Min; Chilukuri, Nageswararao; Brecht, Karen; Maxwell, Donald M.; and Saxena, Ashima, "An In Vitro Comparative Study on the Reactivation of Nerve Agent-Inhibited Guinea Pig and Human Acetylcholinesterases by Oximes" (2007). US Army Research. 42.

https://digitalcommons.unl.edu/usarmyresearch/42

This Article is brought to you for free and open access by the U.S. Department of Defense at DigitalCommons@University of Nebraska - Lincoln. It has been accepted for inclusion in US Army Research by an authorized administrator of DigitalCommons@University of Nebraska - Lincoln. 


\section{Authors}

Chunyuan Luo, Min Tong, Nageswararao Chilukuri, Karen Brecht, Donald M. Maxwell, and Ashima Saxena 


\title{
An In Vitro Comparative Study on the Reactivation of Nerve Agent-Inhibited Guinea Pig and Human Acetylcholinesterases by Oximes
}

\author{
Chunyuan Luo, ${ }^{*}$, Min Tong, ${ }^{\ddagger}$ Nageswararao Chilukuri, ${ }^{*}$ Karen Brecht, ${ }^{\S}$ Donald M. Maxwell, ${ }^{\S}$ and Ashima Saxena \\ Department of Molecular Pharmacology, Division of Biochemistry, Walter Reed Army Institute of Research, \\ Silver Spring, Maryland 20910, and U.S. Army Medical Research Institute of Chemical Defense, Edgewood, Maryland 21010
}

Received May 23, 2007; Revised Manuscript Received July 31, 2007

\begin{abstract}
The reactivation of nerve agent-inhibited acetylcholinesterase (AChE) by oxime is the most important step in the treatment of nerve agent poisoning. Since the evaluation of nerve agent antidotes cannot be conducted in humans, results from animal experiments are extrapolated to humans. Guinea pig is one of the animal models that is frequently used for conducting nerve agent antidote evaluations. Several investigations have demonstrated that the efficacy of an oxime primarily depends on its ability to reactivate nerve agent-inhibited AChE. If the in vitro oxime reactivation of nerve agent-inhibited animal AChE is similar to that of human $\mathrm{AChE}$, it is likely that the results of an in vivo animal study will reliably extrapolate to humans. Therefore, the goal of this study was to compare the reactivation of guinea pig and human AChEs inhibited by six different $\mathrm{G}$ and $\mathrm{V}$ type nerve agents. Reactivation kinetic studies with five monoand bis-pyridinium oximes showed that oxime reactivation of nerve agent-inhibited human AChE in most cases was faster than guinea pig AChE. The most significant enhancement was observed in the reactivation of human AChE inhibited by nerve agents containing bulky side chains GF, GD, and VR, by H-series oximes HLo-7, HI-6, and ICD-585. In these cases, species-related differences observed between the two AChEs, based on the second-order reactivation rate constants, were 90- to over 400-fold. On the other hand, less than 3-fold differences were observed in the rates of aging of nerve agent-inhibited guinea pig and human AChEs. These results suggest that the remarkable species-related differences observed in the reactivation of nerve agent-inhibited guinea pig and human AChEs were not due to differences in the rates of aging. These results also suggest that guinea pig may not be an appropriate animal model for the in vivo evaluation of oxime therapy.
\end{abstract}

Organophosphorus $\left(\mathrm{OP}^{1}\right)$ nerve agents, such as the G-type agents sarin (GB), soman (GD), cyclosarin (GF), and tabun (GA), and V-type agents VX and VR, are a group of highly toxic compounds, which can be utilized as chemical warfare agents. Despite great efforts to prohibit the use of chemical warfare agents by many countries, the threat of these agents is still enormous, as evidenced by the Iran-Iraq war and the Tokyo subway incident in Japan $(1,2)$. The primary target of nerve agents is acetylcholinesterase (AChE; EC 3.1.1.7),

\footnotetext{
* Corresponding author.

Walter Reed Army Institute of Research.

$\S$ U.S. Army Medical Research Institute of Chemical Defense.

${ }^{1}$ Abbreviations: AChE, acetylcholinesterase; GP AChE, guinea pig erythrocyte acetylcholinesterase; $\mathrm{rHu} \mathrm{AChE}$, recombinant human acetylcholinesterase; $\mathrm{BChE}$, butyrylcholinesterase; OP, organophosphorus compounds; DEPQ, 7-(O,O-diethyl-phosphinyloxy)-1-methylquinolinium methylsulfate; GB (sarin), $O$-isopropyl methylphosphonofluoridate; GD (soman), $O$-pinacolyl methylphosphonofluoridate; GF (cyclosarin), $O$-cyclohexyl methylphosphonofluoridate; GA (tabun), $O$-ethyl $N, N$-dimethylphosphoramidocyanate; VX, O-ethyl $S$-2- $N, N$ diisopropylaminoethyl methylphosphonothiolate; VR, $O$-isobutyl $S$-2$\mathrm{N}, \mathrm{N}$-diethylaminoethyl methylphosphonothiolate; 2-PAM, 2-[hydroxyimino methyl]-1-methyl-pyridinium chloride; MMB4, 1,1'-trimethylene bis(4-hydroxyimino methyl) pyridinium dichloride; HI-6, 1-[[[4-(aminocarbonyl)pyridinio]methoxy]methyl]-2-[(hydroxyimino)methyl]-pyridinium dimethanesulfonate; HLo-7, 1-[[[4-(aminocarbonyl)pyridinio]methoxy]methyl]-2,4-bis-[(hydroxylimino)methyl] pyridinium dimethanesulfonate; ICD-585, 1-(2-hydroxyiminomethyl-1-pyridinium)-1'-(4-carboxy-aminopyridinium)-trimethylene hydrochloride; POX, phosphoryl oxime; PIPLC, phosphatidylinositol-specific phospholipase C; BSA, bovine serum albumin.
}

the enzyme that terminates neurotransmission at the postsynapses of cholinergic neurons by catalyzing the hydrolysis of the neurotransmitter acetylcholine. OP nerve agents irreversibly inhibit AChE by forming a covalent adduct with the hydroxyl group of the active site serine, resulting in successive accumulation of acetylcholine, overstimulation of cholinergic receptors, and finally paralysis of neuromuscular functions and death of the victim (3).

The standard treatment for nerve agent poisoning uses a muscarinic antagonist atropine, an oxime reactivator, and an anticonvulsant diazepam, if needed (4). As depicted in Scheme 1, an oxime is used to restore the activity of nerve agent-inhibited AChE, a process called reactivation. This is an important step in the successful treatment of nerve agent poisoning since it is the only practical means for recovering the activity of synaptic AChE inhibited by nerve agents. For this reason, different oxime compounds are used by various countries for the treatment of nerve agent poisoning. For example, the bis-pyridinium oxime obidoxime is used in European countries, while the mono-pyridinium oxime pralidoxime (2-PAM) is used in the United States. The dry powder form of HI-6 is used in auto-injectors in Canada, the only oxime that is a potent reactivator of AChE inhibited by GD and GF (5-7). However, HI-6 does not reactivate AChE inhibited by GA $(8-10)$ and is also a poor reactivator of AChE inhibited by OP pesticides such as paraoxon (11, 12). For this reason, new oximes with broad-spectrum 
Scheme 1: The Reactions for Aging and Oxime Reactivation of Nerve Agent-Inhibited AChE as Represented by AChE-Sarin Conjugate
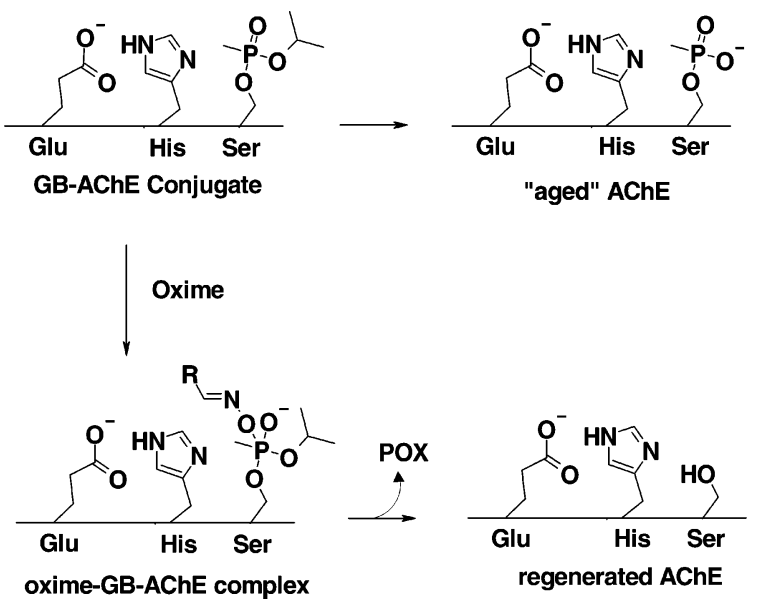

activity in reactivating AChE inhibited by all nerve agents are being actively sought as the next generation of antidotes $(6,13)$.

Since efficacy evaluations of oximes cannot be conducted in humans for ethical reasons, various animal models are used to evaluate nerve agent antidotes, and results from animal studies are extrapolated to humans. Due to the complexity of the in vivo system, the accuracy for extrapolating results from animal studies to humans depends on many factors, such as the distribution and metabolism of the nerve agent and antidote, the sensitivity of the specific OP nerve agent for the inhibition of animal and human AChEs, and differences in the endogenous levels of nerve agent scavenging enzymes, such as butyrylcholinesterase (14), OP hydrolases (15), and carboxylesterase (16). To allow a reasonable animal-to-human extrapolation of experimental results, in vitro comparisons of reactivation of nerve agentinhibited animal and human AChEs by oxime are conducted. The advantages of this method are several-fold. First, kinetic measurements of oxime reactivation yield multiple parameters, such as oxime affinity and oxime reactivity, that can be used to design better oximes. Second, the interaction of an oxime with the pharmacological target (i.e., AChE) is not influenced by its pharmacokinetics and can be more precisely analyzed. Third, AChE reactivation is a more sensitive measure of oxime effectiveness than in vivo survival because the background signal (i.e., AChE activity) for reactivation is much lower than the background signal (i.e., agent $\mathrm{LD}_{50}$ ) for in vivo efficacy in animals. Although this simplified in vitro evaluation does not consider other factors that affect in vivo antidotal efficacy, several investigations have demonstrated that there is a reasonable correlation between in vitro and in vivo data, and the efficacy of an oxime primarily depends on its ability to reactivate nerve agent-inhibited AChE (17-19). If the in vitro oxime reactivation of nerve agent-inhibited animal AChE is similar to that of human $\mathrm{AChE}$, it is likely that the results of in vivo animal study will reliably extrapolate to humans.

The guinea pig is a frequently used animal model for the evaluation of nerve agent antidotes $(7,16,20-21)$. However, there is only one in vitro study reported to date that investigated the oxime reactivation of guinea pig (GP) $\mathrm{AChE}$ (22). Using erythrocyte ghosts as the source of enzyme, significant species-related differences were observed between the oxime reactivation of GB-, GF- and VX-inhibited human, rat, rabbit, and GP AChEs. To further investigate differences in oxime reactivation between nerve agent-inhibited GP and human AChEs, we conducted an in vitro comparative oxime reactivation study using purified GP and recombinant human $(\mathrm{rHu}) \mathrm{AChEs}$ following their inhibition by six different nerve agents (Figure 1). The second-order reactivation rate constants for five different oximes as well as the aging rate constants of nerve agent-inhibited AChEs were determined. Results of this study suggest that, depending on the structures of nerve agents and oximes, differences in oxime reactivation between GP and rHu AChE could be very significant. These results also suggest that guinea pig may not be a suitable animal model for the evaluation of nerve agent antidotes.

\section{MATERIALS AND METHODS}

Purified GP AChE was obtained from $5 \mathrm{~L}$ of packed guinea pig erythrocytes (Harlan, Indianapolis, IN). The dimeric form of GP AChE was released into solution by digestion of the anchor that connects the enzyme to erythrocyte membranes with phosphatidylinositol-specific phospholipase C (PIPLC; 23). The enzyme was then purified by affinity chromatography on a procainamide-Sepharose $4 \mathrm{~B}$ column (Sigma Chemical Co., St. Louis, MO), followed by anion-exchange chromatography on DEAE-Sepharose fast flow column (Amersham Pharmacia, Piscataway, NJ) as described for the purification of fetal bovine serum AChE (24). The specific activity of purified GP AChE was 188 units/nmol as determined by titration with DEPQ (25). The details of the purification procedure will be published elsewhere. Acetylthiocholine iodide (ATC) and 5,5-dithiobis(2-nitrobenzoic acid) (DTNB) were from Sigma Chemical Co. (St. Louis, MO), and Bio-Spin 6 chromatography columns were from Bio-Rad (Hercules, CA). Oximes 2-PAM, HI-6, HLo-7, MMB4, and ICD-585 (Figure 1) were obtained from the Division of Experimental Therapeutics, Walter Reed Army Institute of Research. The purity of all oximes was $>99 \%$ as determined by elemental and HPLC analyses. Nerve agents GB, GD, GF, GA, VX, and VR were obtained from the U.S. Army Edgewood Chemical and Biological Center, Aberdeen Proving Ground, MD. The purity of all nerve agents was $>98.5 \%$ as determined by ${ }^{31} \mathrm{P}$ NMR. Enzyme conjugates with nerve agents GB, GD, GF, GA, VX, and VR were prepared at U.S. Army Medical Research Institute of Chemical Defense (USAMRICD). Recombinant $\mathrm{Hu} \mathrm{AChE}$ was expressed in a Chinese Hamster Ovary $(\mathrm{CHO})$ cell line that was stably transfected with a full-length cDNA for $\mathrm{Hu} \mathrm{AChE}$, which was a generous gift from Dr. Oksana Lockridge (Eppley Institute, University of Nebraska Medical Center, Omaha, NE). The enzyme purified by affinity chromatography on procainamide-Sepharose 4B affinity column had a specific activity of 345 units $/ \mathrm{nmol}$.

AChE Assay. AChE activity was determined by the Ellman method (26). The assay mixture contained $1 \mathrm{mM} \mathrm{ATC} \mathrm{as}$ the substrate and $0.5 \mathrm{mM}$ DTNB in $50 \mathrm{mM}$ sodium phosphate buffer, $\mathrm{pH}$ 8.0. The formation of product was measured at $412 \mathrm{~nm}$ at $25{ }^{\circ} \mathrm{C}$.

Determination of Rate Constants for the Reactivation of Nerve Agent-Inhibited AChEs by Oximes. Kinetic constants for the reactivation of nerve agent-inhibited AChEs were 
<smiles>CC(C)OP(C)(=O)F</smiles>

Sarin<smiles>CCOP(=O)(C#N)N(C)CC</smiles>

Tabun<smiles>CC(OP(C)(=O)F)C(C)(C)C</smiles>

Soman<smiles>CP(=O)(F)OC1CCCCC1</smiles>

GF
$\overbrace{\mathrm{CH}_{3}}^{\mathrm{O}-\mathrm{C}_{2} \mathrm{H}_{5}} \underset{\mathrm{SCH}_{2} \mathrm{CH}_{2} \mathrm{~N}\left(\text { isoC }_{3} \mathrm{H}_{7}\right)_{2}}{\mathrm{O}}$

vX<smiles>CCC(C)OP(C)(=O)SCCN(CC)CC</smiles>

VR<smiles></smiles><smiles></smiles>

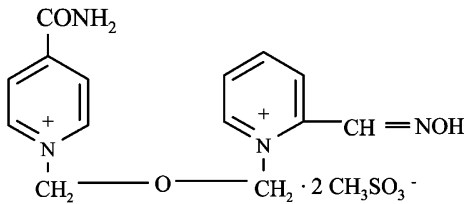

2-PAM

MMB4

HI-6

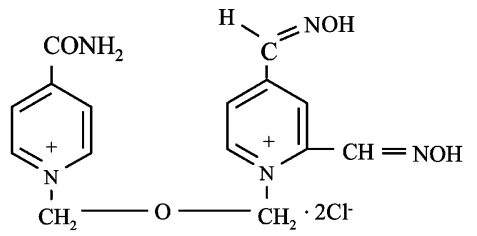

HLo-7

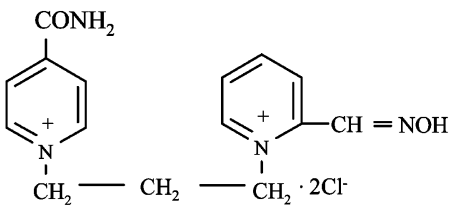

ICD-585

FIGURE 1: Structures of nerve agents and oximes used in the study.

determined using a noncontinuous method (27). In order to minimize the aging of nerve agent-inhibited AChEs, enzyme conjugates for reactivation studies were prepared in $100 \mathrm{mM}$ TAPS buffer, $\mathrm{pH}$ 9.5. Excess nerve agent was either removed from $\mathrm{AChE}$-nerve agent conjugate by passing the solution through a Bio-Spin 6 column or neutralized by adding fresh enzyme to the solution. AChE-nerve agent conjugates were stored at $-20{ }^{\circ} \mathrm{C}$ in $50 \%$ glycerol until use. Oxime reactivation was initiated by making at least a 20-fold dilution of the AChE-nerve agent conjugate in $50 \mathrm{mM}$ sodium phosphate buffer, $\mathrm{pH} 8.0$, containing $0.05 \%$ bovine serum albumin (BSA) and different concentrations of oxime. The solution was maintained at $22{ }^{\circ} \mathrm{C}$, and at specified time intervals, $5-10 \mu \mathrm{L}$ of the reactivation mixture was transferred into a cuvette containing $1-3 \mathrm{~mL}$ of assay mixture, to monitor AChE activity. The final concentration of enzyme in the assay mixture varied from 0.01 to $0.04 \mathrm{nM}$. Three control groups (AChE control, nerve agent-inhibited AChE control, and AChE with oxime control) were also set up for the simultaneous monitoring of AChE activity at different time intervals. Four to six oxime concentrations ranging from $1 \mu \mathrm{M}$ to $3.2 \mathrm{mM}$ were used for determining the reactivation rate constants depending on the oxime and OP conjugate. In order to minimize the possible reinhibition of reactivated enzyme by phosphoryl oxime (POX) and to ensure an accurate determination of the reactivation rate constants, the concentration of $\mathrm{AChE}$-nerve agent conjugate was kept as low as possible (25). The first-order reactivation rate constant, $k_{\text {obs, }}$ was determined by fitting the experimental data to the equation for one-phase exponential association:

$$
\%\left(E_{\text {react }}\right)_{t}=A\left(1-\mathrm{e}^{-k_{\text {obs }} t}\right)
$$

where $t$ is the time at which the sample was withdrawn; \% $\left(E_{\text {react }}\right)_{t}$ is percent reactivation measured at time $t$; and $A$ is percent of maximum reactivation measured after $24 \mathrm{~h}$.

A secondary plot of $k_{\text {obs }}$ versus [oxime] was used to obtain the second-order reactivation rate constant:

$$
\begin{gathered}
k_{\mathrm{obs}}=k_{2} /\left(1+K_{\mathrm{ox}} /[\text { oxime }]\right) \\
k_{\mathrm{r}}=k_{2} / K_{\mathrm{ox}}
\end{gathered}
$$

where $k_{2}$ is the intrinsic reaction constant; $K_{\mathrm{ox}}$ is the apparent equilibrium constant; and $k_{\mathrm{r}}$ is the second-order reactivation rate constant.

Since aging (dealkylation) of GD-inhibited AChE is very fast (half-life of aging is 6 to $20 \mathrm{~min}$ under the experimental conditions), reactivation was always significantly lower than predicted by the theoretical model if aging was not taken into account. Therefore, reactivation data were analyzed using 

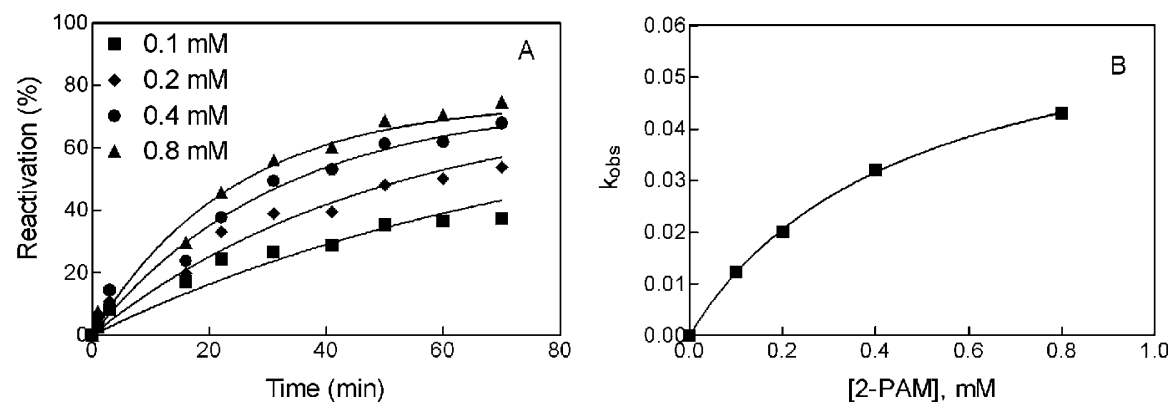

FIGURE 2: Reactivation kinetics of GB-inhibited rHu AChE by 2-PAM. Panel A: Reactivation kinetics of GB-inhibited rHu AChE by four different concentrations of 2-PAM $(0.1$ to $0.8 \mathrm{mM})$. Panel B: Secondary plot of the $k_{\mathrm{obs}} \mathrm{vs}$ [2-PAM] for the calculation of reactivation rate constants.
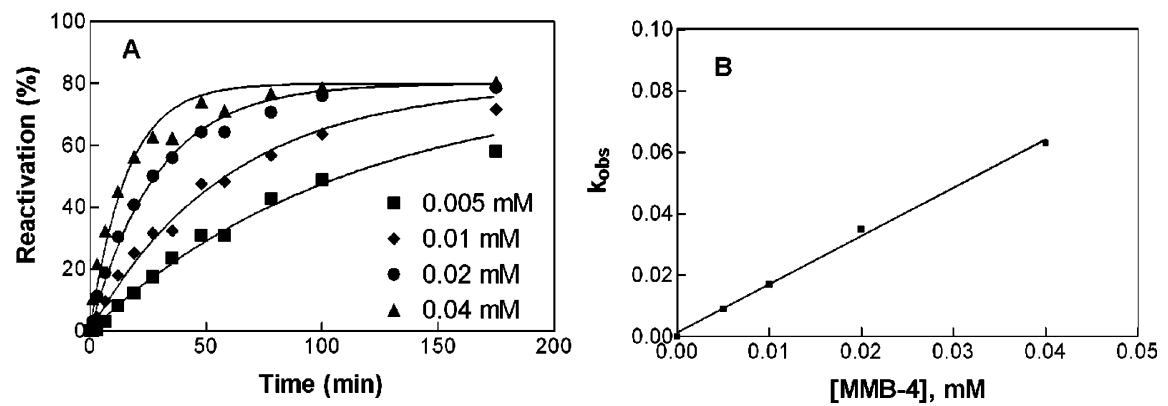

FIGURE 3: Reactivation kinetics of GF-inhibited $\mathrm{rHu}$ AChE by MMB4. Panel A: Reactivation kinetics of GF-inhibited rHu AChE by four different concentrations of MMB4 (0.005 to $0.04 \mathrm{mM})$. Panel B: Secondary plot of the $k_{\mathrm{obs}}$ vs [MMB4] for the calculation of second-order reactivation rate constant.

the following equation that accounts for two rates simultaneously:

$$
\%\left(E_{\text {react }}\right)_{t}=k_{\text {obs }} A /\left(k_{\text {obs }}+k_{\mathrm{a}}\right)\left(1-\mathrm{e}^{-\left(k_{\mathrm{obs}}+k_{\mathrm{a}}\right) t}\right)
$$

where $k_{\mathrm{a}}$ is the aging rate constant for nerve agent-inhibited $\mathrm{AChE}$. This equation originally was used to calculate the aging and spontaneous reactivation of GF-inhibited $\mathrm{BChE}$ by Worek et al. (28). Since the spontaneous reactivation of GD-inhibited AChE is negligible, $k_{\mathrm{obs}}$ in this case represents oxime-induced reactivation. Though the fit was significantly improved with this equation, deviations between the fit and the actual data were sometimes still significant. This may be due to the effect of different oximes on the rate of aging of GD-inhibited AChE as reported previously (29).

Determination of the Aging Rate Constants of Nerve Agent-Inhibited AChEs. The aging rate constants of nerve agent-inhibited AChEs were measured in $50 \mathrm{mM}$ sodium phosphate buffer, $\mathrm{pH} 8.0$, at $37^{\circ} \mathrm{C}$. AChE-nerve agent conjugates prepared in $100 \mathrm{mM}$ TAPS buffer, $\mathrm{pH}$ 9.5, were diluted at least 20 -fold with $50 \mathrm{mM}$ sodium phosphate buffer, $\mathrm{pH} 8.0$, containing $0.1 \%$ BSA. Aliquots of enzyme $(10 \mu \mathrm{L})$ were withdrawn at different time intervals, and transferred to tubes containing $0.2-1 \mathrm{mM}$ oxime. TMB4 was used for GA-inhibited GP and $\mathrm{rHu}$ AChEs, while HLo-7 was used for all other AChE-nerve agent conjugates. The samples were assayed for AChE activity after incubation for $5 \mathrm{~h}$ to ensure the maximum reactivation of the nerve agent-inhibited AChE. The aging rate constant $\left(k_{\mathrm{a}}\right)$ of nerve agent-inhibited $\mathrm{AChE}$ was calculated according to the following equation for first-order decay:

$$
\%\left(E_{\text {react }}\right)_{\mathrm{t}}=A \mathrm{e}^{-k_{\mathrm{a}} t}
$$

where $A$ is the maximum percent reactivation of $\mathrm{AChE}$ activity after incubation with oxime and $t$ is the time at which aliquots of enzyme were withdrawn.

\section{RESULTS}

Reactivation of G Agent-Inhibited GP and Hu AChEs by Oximes. GP and $\mathrm{rHu}$ AChEs were inhibited by four different G-type nerve agents, and reactivation kinetic studies were conducted with five different mono- and bis-pyridinium oximes. Examples of reactivation kinetics are shown in Figures 2A and 2B. In Figure 2B, where the secondary plot followed a saturation curve, the second-order reactivation rate constant $\left(k_{\mathrm{r}}\right)$ was obtained from the ratio of $k_{2} / K_{\mathrm{ox}}$. In cases where a linear correlation was observed instead of the saturation curve as shown in Figure $3 \mathrm{~B}, k_{2}$ and $K_{\mathrm{ox}}$ could not be determined and $k_{\mathrm{r}}$ was estimated from the slope of the line. As mentioned above, only partial reactivations of GD-inhibited GP and rHu AChEs were achieved due to their fast aging, and $k_{\mathrm{obs}}$ were obtained by fitting the experimental data to eq 4 to accommodate the effect of aging (Figures 4A and 4B). Kinetic rate constants $\left(k_{2}, K_{\mathrm{ox}}, k_{\mathrm{r}}\right)$ for the reactivation of different $\mathrm{G}$ agent-inhibited $\mathrm{GP}$ and $\mathrm{rHu}$ AChEs are summarized in Tables 1-4. Results show that except for GA-inhibited GP and $\mathrm{rHu}$ AChEs which could not be reactivated by HI-6 and ICD-585, the reactivation rates of $\mathrm{rHu} \mathrm{AChE}$ inhibited by all four $\mathrm{G}$ agents were faster than those for GP AChE. However, differences in the secondorder reactivation constants between these two enzymes depend both on the oxime and on the nerve agent used and vary from a little over 1 -fold to 435 -fold. Smaller apparent equilibrium constants $\left(K_{\mathrm{ox}}\right)$ coupled with faster intrinsic reaction constants $\left(k_{2}\right)$ were generally observed for the reactivation of $\mathrm{rHu} \mathrm{AChE}$-nerve agent by the four bispyridinium oximes. These differences were generally more 

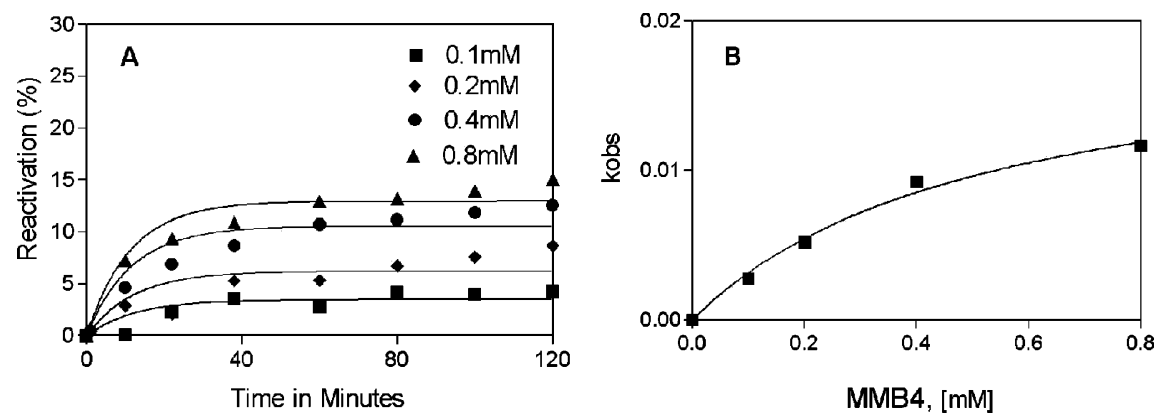

FIGURE 4: Reactivation kinetics of GD-inhibited GP AChE by MMB4. Panel A: Reactivation kinetics of GD-inhibited GP AChE by four different concentrations of MMB4 (0.1 to $0.8 \mathrm{mM})$; data were fit to eq 4 for the calculation of $k_{\text {obs }}$ for each oxime concentration. Panel B: Secondary plot of $k_{\mathrm{obs}}$ vs [MMB4] for the calculation of second-order reactivation rate constant.

Table 1: Rate Constants ${ }^{a}$ for the Reactivation of GB-Inhibited GP and Hu AChEs by Different Oximes

\begin{tabular}{|c|c|c|c|c|c|c|}
\hline \multirow[b]{2}{*}{ oxime } & \multicolumn{3}{|c|}{ GP AChE } & \multicolumn{3}{|c|}{ rHu AChE } \\
\hline & $\begin{array}{c}k_{2} \\
\left(\min ^{-1}\right)\end{array}$ & $\begin{array}{c}K_{\mathrm{ox}} \\
(\mathrm{mM})\end{array}$ & $\begin{array}{c}k_{\mathrm{r}} \\
\left(\mathrm{mM}^{-1} \min ^{-1}\right)\end{array}$ & $\begin{array}{c}k_{2} \\
\left(\min ^{-1}\right)\end{array}$ & $\begin{array}{c}K_{\mathrm{ox}} \\
(\mathrm{mM})\end{array}$ & $\begin{array}{c}k_{\mathrm{r}} \\
\left(\mathrm{mM}^{-1} \min ^{-1}\right)\end{array}$ \\
\hline 2-PAM & $0.070 \pm 0.022$ & $0.342 \pm 0.126$ & 0.206 & $0.123 \pm 0.032$ & $0.266 \pm 0.150$ & 0.462 \\
\hline MMB4 & $0.076 \pm 0.005$ & $0.294 \pm 0.031$ & 0.257 & $\mathrm{nd}^{b}$ & $\mathrm{nd}^{b}$ & 0.770 \\
\hline HI-6 & $0.020 \pm 0.007$ & $0.067 \pm 0.012$ & 0.297 & $0.128 \pm 0.011$ & $0.022 \pm 0.010$ & 5.953 \\
\hline HLo-7 & $0.070 \pm 0.009$ & $0.100 \pm 0.029$ & 0.696 & $0.320 \pm 0.046$ & $0.028 \pm 0.010$ & 11.430 \\
\hline ICD-585 & $0.039 \pm 0.021$ & $0.147 \pm 0.045$ & 0.267 & $0.157 \pm 0.066$ & $0.072 \pm 0.030$ & 2.160 \\
\hline
\end{tabular}

${ }^{a}$ Data are means \pm standard errors from 2-4 determinations. ${ }^{b}$ Value could not be determined due to the linear relationship of $k_{\mathrm{obs}} \mathrm{vs}$ [oxime].

Table 2: Rate Constants ${ }^{a}$ for the Reactivation of GD-Inhibited GP and Hu AChEs by Different Oximes

\begin{tabular}{|c|c|c|c|c|c|c|}
\hline \multirow[b]{2}{*}{ oxime } & \multicolumn{3}{|c|}{ GP AChE } & \multicolumn{3}{|c|}{ rHu AChE } \\
\hline & $\begin{array}{c}k_{2} \\
\left(\min ^{-1}\right)\end{array}$ & $\begin{array}{c}K_{\mathrm{ox}} \\
(\mathrm{mM})\end{array}$ & $\begin{array}{c}k_{\mathrm{r}} \\
\left(\mathrm{mM}^{-1} \min ^{-1}\right)\end{array}$ & $\begin{array}{c}k_{2} \\
\left(\mathrm{~min}^{-1}\right)\end{array}$ & $\begin{array}{c}K_{\mathrm{ox}} \\
(\mathrm{mM})\end{array}$ & $\begin{array}{c}k_{\mathrm{r}} \\
\left(\mathrm{mM}^{-1} \min ^{-1}\right)\end{array}$ \\
\hline 2-PAM & $0.029 \pm 0.009$ & $1.730 \pm 0.24$ & 0.017 & $0.262 \pm 0.113$ & $5.090 \pm 1.590$ & 0.052 \\
\hline MMB4 & $0.064 \pm 0.020$ & $2.310 \pm 0.520$ & 0.038 & $\mathrm{nd}^{b}$ & $\mathrm{nd}^{b}$ & 0.785 \\
\hline HI-6 & $0.026 \pm 0.013$ & $0.910 \pm 0.310$ & 0.051 & $0.183 \pm 0.040$ & $0.009 \pm 0.004$ & 21.510 \\
\hline HLo-7 & $0.067 \pm 0.026$ & $0.490 \pm 0.170$ & 0.140 & $0.307 \pm 0.080$ & $0.012 \pm 0.006$ & 26.180 \\
\hline ICD-585 & $0.015 \pm 0.004$ & $1.310 \pm 0.480$ & 0.012 & $0.432 \pm 0.161$ & $0.170 \pm 0.048$ & 2.540 \\
\hline
\end{tabular}

${ }^{a}$ Due to the rapid aging of GD-inhibited GP and Hu AChEs, reactivation by oximes was immediately started after inhibition of AChE by GD in $\mathrm{pH} 9.5$ buffer, and $k_{\mathrm{obs}}$ at each oxime concentration was obtained by fitting the data to eq 4 . Data are means \pm standard errors from $2-4$ determinations. ${ }^{b}$ Value could not be determined due to the linear relationship of $k_{\text {obs }}$ vs [oxime].

Table 3: Rate Constants ${ }^{a}$ for the Reactivation of GF-Inhibited GP and Hu AChEs by Different Oximes

\begin{tabular}{|c|c|c|c|c|c|c|}
\hline \multirow[b]{2}{*}{ oxime } & \multicolumn{3}{|c|}{ GP AChE } & \multicolumn{3}{|c|}{$\mathrm{rHu} \mathrm{AChE}$} \\
\hline & $\begin{array}{c}k_{2} \\
\left(\min ^{-1}\right)\end{array}$ & $\begin{array}{c}K_{\mathrm{ox}} \\
(\mathrm{mM})\end{array}$ & $\begin{array}{c}k_{\mathrm{r}} \\
\left(\mathrm{mM}^{-1} \min ^{-1}\right)\end{array}$ & $\begin{array}{c}k_{2} \\
\left(\min ^{-1}\right)\end{array}$ & $\begin{array}{c}K_{\mathrm{ox}} \\
(\mathrm{mM})\end{array}$ & $\begin{array}{c}k_{\mathrm{r}} \\
\left(\mathrm{mM}^{-1} \min ^{-1}\right)\end{array}$ \\
\hline 2-PAM & $0.016 \pm 0.004$ & $2.234 \pm 0.380$ & 0.007 & $0.035 \pm 0.012$ & $1.247 \pm 0.650$ & 0.028 \\
\hline MMB4 & $0.277 \pm 0.062$ & $1.981 \pm 0.434$ & 0.140 & $\mathrm{nd}^{b}$ & $\mathrm{nd}^{b}$ & 5.100 \\
\hline HI-6 & $0.067 \pm 0.054$ & $0.506 \pm 0.323$ & 0.133 & $1.040 \pm 0.240$ & $0.035 \pm 0.016$ & 29.700 \\
\hline HLo-7 & $0.076 \pm 0.029$ & $0.383 \pm 0.288$ & 0.139 & $1.620 \pm 0.453$ & $0.019 \pm 0.006$ & 85.060 \\
\hline ICD-585 & $0.039 \pm 0.021$ & $0.226 \pm 0.053$ & 0.174 & $0.320 \pm 0.070$ & $0.020 \pm 0.040$ & 15.790 \\
\hline
\end{tabular}

${ }^{a}$ Data are means \pm standard errors from $2-4$ determinations. ${ }^{b}$ Value could not be determined due to the linear relationship of $k_{\mathrm{obs}} \mathrm{vs}$ [oxime].

pronounced for the reactivation of GD- and GF-inhibited enzymes by HI-6, HLo-7, and ICD-585. Differences in the second-order reactivation rate constants between these two enzymes were much smaller with the mono-pyridinium oxime 2-PAM, with $k_{\mathrm{r}}$ s for GB-, GD-, and GF-inhibited $\mathrm{rHu}$ AChE being only 1.2- to 3-fold faster than GP AChE. The enzyme conjugates with GA were more resistant to reactivation by oximes compared to other conjugates, and no noticeable reactivation was observed with HI-6 or ICD-585. The $k_{\mathrm{r}}$ of GA-inhibited $\mathrm{rHu} \mathrm{AChE}$ was 2- to 15-fold higher than that for GP AChE with 2-PAM, MMB4, and HLo-7. The best oxime for GA-inhibited AChE was HLo-7, with a $k_{\mathrm{r}}$ of $62 \mathrm{M}^{-1} \mathrm{~min}^{-1}$.
Reactivation of V Agent-Inhibited GP and Hu AChEs by Oximes. Oxime reactivation studies were also conducted with GP and rHu AChEs inhibited by V-type nerve agents VX and VR. Since the stereoselectivity of VX is significantly less for the inhibition of $\mathrm{AChE}$ than with other nerve agents such as GB and GD (30-32), both enantiomers of VX inhibit AChE, yielding two different AChE-OP conjugates that are reactivated at different rates by oxime (33). Also, AChEVX conjugates corresponding to the two enantiomers were not at a 1:1 ratio; therefore, a mathematical solution to obtain individual reactivation rate constants for each species in the mixture was difficult. The experimental data were fitted using a one-phase exponential association model to calculate an 


\begin{tabular}{|c|c|c|c|c|c|c|}
\hline \multirow[b]{2}{*}{ oxime } & \multicolumn{3}{|c|}{ GP AChE } & \multicolumn{3}{|c|}{ rHu AChE } \\
\hline & $\begin{array}{c}k_{2} \\
\left(\min ^{-1}\right)\end{array}$ & $\begin{array}{c}K_{\mathrm{ox}} \\
(\mathrm{mM})\end{array}$ & $\begin{array}{c}k_{\mathrm{r}} \\
\left(\mathrm{mM}^{-1} \min ^{-1}\right)\end{array}$ & $\begin{array}{c}k_{2} \\
\left(\min ^{-1}\right)\end{array}$ & $\begin{array}{c}K_{\mathrm{ox}} \\
(\mathrm{mM})\end{array}$ & $\begin{array}{c}k_{\mathrm{r}} \\
\left(\mathrm{mM}^{-1} \min ^{-1}\right)\end{array}$ \\
\hline 2-PAM & $0.002 \pm 0.001$ & $1.210 \pm 0.340$ & 0.002 & $0.008 \pm 0.006$ & $1.320 \pm 0.770$ & 0.006 \\
\hline MMB4 & $0.006 \pm 0.001$ & $10.580 \pm 2.450$ & 0.001 & $0.013 \pm 0.008$ & $2.990 \pm 1.230$ & 0.004 \\
\hline HI-6 & $\mathrm{nd}^{b}$ & $\mathrm{nd}^{b}$ & $\mathrm{nd}^{b}$ & $\mathrm{nd}^{b}$ & $\mathrm{nd}^{b}$ & $\mathrm{nd}^{b}$ \\
\hline HLo-7 & $0.003 \pm 0.002$ & $0.720 \pm 0.410$ & 0.004 & $0.005 \pm 0.001$ & $0.080 \pm 0.004$ & 0.062 \\
\hline ICD-585 & $\mathrm{nd}^{b}$ & $\mathrm{nd}^{b}$ & $\mathrm{nd}^{b}$ & $\mathrm{nd}^{b}$ & $\mathrm{nd}^{b}$ & $\mathrm{nd}^{b}$ \\
\hline
\end{tabular}

${ }^{a}$ Data are means \pm standard errors from 2-4 determinations. ${ }^{b}$ Reactivation was so insignificant that the reactivation kinetic constants could not be calculated.

\begin{tabular}{|c|c|c|c|c|c|c|}
\hline \multirow[b]{2}{*}{ oxime } & \multicolumn{3}{|c|}{ GP AChE } & \multicolumn{3}{|c|}{$\mathrm{rHu} \mathrm{AChE}$} \\
\hline & $\begin{array}{c}k_{2} \\
\left(\mathrm{~min}^{-1}\right)\end{array}$ & $\begin{array}{c}K_{\mathrm{ox}} \\
(\mathrm{mM})\end{array}$ & $\begin{array}{c}k_{\mathrm{r}} \\
\left(\mathrm{mM}^{-1} \min ^{-1}\right)\end{array}$ & $\begin{array}{c}k_{2} \\
\left(\min ^{-1}\right)\end{array}$ & $\begin{array}{c}K_{\mathrm{ox}} \\
(\mathrm{mM})\end{array}$ & $\begin{array}{c}k_{\mathrm{r}} \\
\left(\mathrm{mM}^{-1} \min ^{-1}\right)\end{array}$ \\
\hline 2-PAM & $0.012 \pm 0.001$ & $0.074 \pm 0.005$ & 0.160 & $0.031 \pm 0.013$ & $0.272 \pm 0.121$ & 0.117 \\
\hline MMB4 & $0.184 \pm 0.072$ & $2.238 \pm 1.475$ & 0.082 & $0.024 \pm 0.008$ & $0.137 \pm 0.060$ & 0.177 \\
\hline HI-6 & $0.004 \pm 0.001$ & $0.057 \pm 0.002$ & 0.074 & $0.014 \pm 0.005$ & $0.014 \pm 0.008$ & 1.045 \\
\hline HLo-7 & $0.024 \pm 0.004$ & $0.088 \pm 0.006$ & 0.267 & $0.018 \pm 0.007$ & $0.004 \pm 0.001$ & 4.230 \\
\hline ICD-585 & $0.007 \pm 0.001$ & $0.059 \pm 0.021$ & 0.124 & $0.013 \pm 0.005$ & $0.018 \pm 0.007$ & 0.670 \\
\hline
\end{tabular}

${ }^{a}$ Data are means \pm standard errors from $2-4$ determinations.

Table 6: Rate Constants ${ }^{a}$ for the Reactivation of VR-Inhibited GP and Hu AChEs by Different Oximes

\begin{tabular}{|c|c|c|c|c|c|c|}
\hline \multirow[b]{2}{*}{ oxime } & \multicolumn{3}{|c|}{ GP AChE } & \multicolumn{3}{|c|}{ rHu AChE } \\
\hline & $\begin{array}{c}k_{2} \\
\left(\min ^{-1}\right)\end{array}$ & $\begin{array}{c}K_{\mathrm{ox}} \\
(\mathrm{mM})\end{array}$ & $\begin{array}{c}k_{\mathrm{r}} \\
\left(\mathrm{mM}^{-1} \min ^{-1}\right)\end{array}$ & $\begin{array}{c}k_{2} \\
\left(\min ^{-1}\right)\end{array}$ & $\begin{array}{c}K_{\mathrm{ox}} \\
(\mathrm{mM})\end{array}$ & $\begin{array}{c}k_{\mathrm{r}} \\
\left(\mathrm{mM}^{-1} \min ^{-1}\right)\end{array}$ \\
\hline 2-PAM & $0.016 \pm 0.007$ & $2.230 \pm 0.320$ & 0.017 & $0.080 \pm 0.030$ & $0.317 \pm 0.112$ & 0.252 \\
\hline MMB4 & $0.277 \pm 0.043$ & $1.980 \pm 0.262$ & 0.140 & $\mathrm{nd}^{b}$ & $\mathrm{nd}^{b}$ & 1.760 \\
\hline HI-6 & $0.134 \pm 0.027$ & $0.166 \pm 0.041$ & 0.081 & $0.225 \pm 0.033$ & $0.012 \pm 0.002$ & 19.580 \\
\hline HLo-7 & $0.066 \pm 0.016$ & $0.272 \pm 0.132$ & 0.243 & $0.582 \pm 0.340$ & $0.013 \pm 0.004$ & 43.80 \\
\hline ICD-585 & $0.015 \pm 0.068$ & $0.184 \pm 0.030$ & 0.082 & $0.872 \pm 0.280$ & $0.051 \pm 0.018$ & 16.760 \\
\hline
\end{tabular}

${ }^{a}$ Data are means \pm standard errors from $2-4$ determinations. ${ }^{b}$ Values could not be determined due to the linear relationship of $k_{\mathrm{obs}}$ vs [oxime].

average rate constant for the reactivation of $\mathrm{VX}$-inhibited AChE. Rate constants for the reactivation of VX- and VRinhibited GP and $\mathrm{rHu}$ AChEs by different oximes are summarized in Tables 5 and 6, respectively. Results showed that with VR-inhibited AChEs, differences between GP and $\mathrm{rHu}$ AChEs were similar to those observed with GF, GD, and GB. The second-order reactivation rate constants by these five oximes were 12- to 211-fold faster for $\mathrm{rHu} \mathrm{AChE}$ than GP AChE, which were due to both faster $k_{2}$ and lower binding affinity (higher $K_{\mathrm{ox}}$ ). But the differences were smaller with VX-inhibited enzymes. The most significant difference was observed with HLo-7, where $k_{\mathrm{r}}$ was 15 -fold faster for VX-inhibited $\mathrm{rHu}$ AChE than that for GP AChE. With the mono-pyridinium oxime 2-PAM, the reactivation of VXinhibited $\mathrm{rHu}$ AChE was a little slower than that of GP AChE. In most cases, the faster $k_{\mathrm{r}}$ values of VX-inhibited $\mathrm{rHu} \mathrm{AChE}$ were mainly due to the higher binding affinity of oximes for $\mathrm{rHu} \mathrm{AChE}$ conjugates than for GP AChE conjugates.

A comparison of $k_{\mathrm{r}}$ values for oxime reactivation of nerve agent-inhibited GP and $\mathrm{rHu}$ AChEs is shown in Figure 5. By assigning a value of 1 to the $k_{\mathrm{r}}$ for GP AChE, each bar in Figure 5 represents the relative potency of an oxime for the reactivation of $\mathrm{rHu} \mathrm{AChE}$ inhibited by the nerve agent compared to that for GP AChE. Data shows that the oxime reactivation of nerve agent-inhibited $\mathrm{rHu} \mathrm{AChE}$ was generally faster than that of GP AChE. The most pronounced differences were observed when GF-, GD-, and VR-inhibited AChEs when reactivated by HLo-7, HI-6, and ICD-585, with

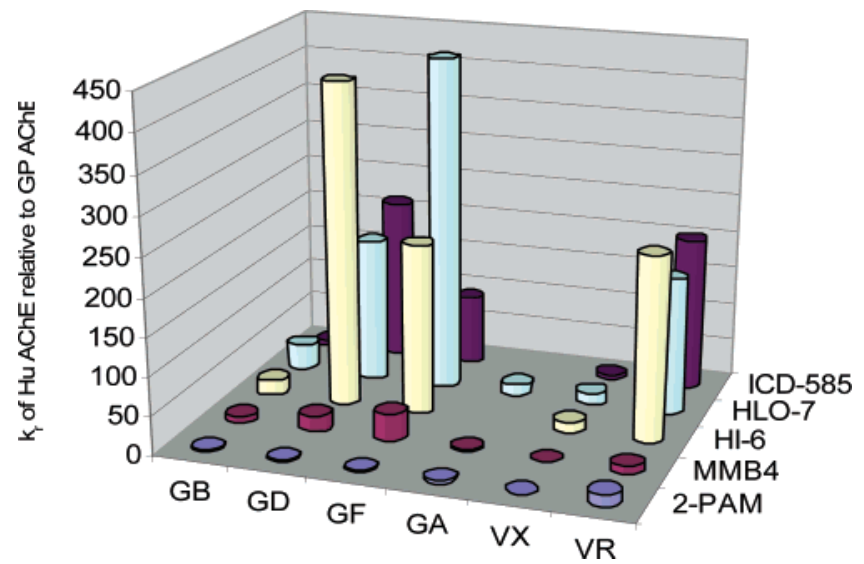

FIGURE 5: The ratios of the second-order oxime reactivation rate constants of nerve agent-inhibited $\mathrm{rHu} \mathrm{AChE}$ and GP AChE for different oximes. The bars in the graph represent the ratios of $k_{\mathrm{r}}$ values between reactivation of nerve agent-inhibited $\mathrm{rHu} \mathrm{AChE}$ and GP AChE by the same oxime.

$k_{\mathrm{r}}$ values that were 90- to 435 -fold higher. Differences of less than 20-fold were observed in the oxime reactivation of two enzymes inhibited with other nerve agents, except for the reactivation of GF-inhibited AChEs by MMB4 and GB-inhibited AChEs by HLo-7, where up to 30-fold differences were observed.

Aging Rate Constants of Nerve Agent-Inhibited GP and $\mathrm{Hu}$ AChEs. The aging of GP and $\mathrm{rHu}$ AChEs inhibited by six different nerve agents was examined by determining the maximum reactivation obtained after incubation of the 
Table 7: Aging Rate Constants $^{a}\left(k_{\mathrm{a}}\right)$ for Nerve Agent-Inhibited GP and rHu AChEs

\begin{tabular}{cllllll}
\hline & \multicolumn{5}{c}{$k_{\mathrm{a}}, \mathrm{h}^{-1} \times 10^{-2}$} \\
\cline { 2 - 6 } enzyme & \multicolumn{1}{c}{ GB } & \multicolumn{1}{c}{ GD } & \multicolumn{1}{c}{ GF } & \multicolumn{1}{c}{ GA } & \multicolumn{1}{c}{ VX } \\
\hline GP AChE & $5.33 \pm 0.64$ & $167.61 \pm 43.25$ & $0.91 \pm 0.06$ & $0.94 \pm 0.07$ & $0.18 \pm 00.04$ & $0.21 \pm 0.02$ \\
& $(13)$ & $(0.42)$ & $(76)$ & $(73)$ & $(380)$ & $(325)$ \\
rHu AChE & $6.45 \pm 0.67$ & $677.64 \pm 103.62$ & $1.69 \pm 0.17$ & $0.70 \pm 0.08$ & $0.19 \pm 0.05$ & $\mathrm{nd}^{b}$ \\
& $(11)$ & $(0.1)$ & $(41)$ & $(99)$ & $(357)$ & \\
\hline
\end{tabular}

${ }^{a}$ Values of $k_{\mathrm{a}} \mathrm{s}$ and the least-squares errors were determined in $50 \mathrm{mM}$ sodium phosphate buffer, pH 8.0, at $37{ }^{\circ} \mathrm{C}$; values in parentheses are half-times for aging in hours. ${ }^{b} \mathrm{ND}$, not determined.

AChE-OP conjugates in $50 \mathrm{mM}$ phosphate buffer, $\mathrm{pH} 8.0$, containing an oxime, at $37{ }^{\circ} \mathrm{C}$. In each case, the most effective oxime was used. The aging rate constants and the half-times of aging are summarized in Table 7. Results showed that the most significant difference in aging was observed with GD-inhibited AChEs, since GD-inhibited rHu AChE aged 3 times faster than GP AChE. The aging of GFinhibited $\mathrm{rHu} \mathrm{AChE}$ was also $70 \%$ faster than that of GP AChE. For AChEs inhibited by GB, GA, and VX, there were no significant differences between these two enzymes. The aging of VR-inhibited $\mathrm{rHu} \mathrm{AChE}$ could not determined due to the relatively poor stability of $\mathrm{rHu} \mathrm{AChE}$ at $37^{\circ} \mathrm{C}$ and the fast spontaneous reactivation of $\mathrm{VR}-\mathrm{AChE}$ conjugate. However, the half-time of aging of $325 \mathrm{~h}$ for VR-inhibited GP AChE suggests that the aging of rHu AChE-VR conjugate should not significantly affect oxime reactivation.

\section{DISCUSSION}

$\mathrm{AChE}$ is one of the most efficient enzymes, with a turnover number of over $10^{-4} \mathrm{~s}^{-1}(34)$. This high catalytic efficiency is maintained in AChEs across animal species as indicated by the high homology in the amino acid sequences of these enzymes. Despite this high homology, many studies have revealed significant species-related differences between these enzymes with regard to interaction with inhibitors (35-39). On the other hand, most oxime reactivation studies with enzyme-OP conjugates from different AChEs only indicated moderate species-related variations in reactivation rates $(27$, $40,41)$, with the exception of HI-6, which showed that the reactivation of GD-inhibited eel AChE was remarkably slower than that of $\mathrm{Hu} \mathrm{AChE}(42,43)$. More recently, notable species-related differences between the reactivation of GP and $\mathrm{Hu} \mathrm{AChE}$ were reported when guinea pig or pig and human erythrocyte ghost cell AChEs were compared (22, 44). Since guinea pig is a frequently used animal model for evaluating oxime therapy, these results indicate that speciesrelated differences in oxime reactivation between GP and $\mathrm{Hu} \mathrm{AChE}$ may be problematic in extrapolating experimental animal data to humans. Therefore, in this study, we conducted a complete characterization of the aging and reactivation properties of purified GP and rHu AChEs. This comprehensive reactivation study using six classical OP nerve agents and five different oximes revealed novel and interesting differences between the oxime reactivation of nerve agent-inhibited GP and $\mathrm{rHu}$ AChEs. In general, the reactivation of $\mathrm{rHu}$ AChE inhibited by different G- and V-type nerve agents by these oximes was faster than GP AChE. The most pronounced species-related differences were observed in the reactivation of GF-, GD-, and VR-inhibited AChEs by HLo-7, HI-6, and ICD-585. In these cases, the second-order reactivation rate constants of $\mathrm{rHu} \mathrm{AChE}$ were
90- to 435-fold higher than those for GP AChE. With the mono-pyridinium oxime 2-PAM, the differences between these two AChEs were much smaller, and in some cases the reactivation was faster for GP AChE. These results strongly suggest that the guinea pig may be not a suitable animal model for the in vivo screening of oximes for the development of antidotes for humans, since the use of equal molar doses in this animal model may lead to an assessment of oxime efficacies which is not appropriate for humans. Similarly, some potential oximes that are suitable for humans may be dismissed based upon their poor efficacy in guinea pigs.

For the reactivation of all six enzyme-nerve agent conjugates by most of the tested oximes, the plot of $k_{\mathrm{obs}} \mathrm{vs}$ [oxime] followed a saturation curve, which allowed the determination of both the $K_{\mathrm{ox}}$ and $k_{2}$ as shown in Tables 1 to 6. However, kinetics for MMB4 reactivation of $\mathrm{rHu}$ AChEs inhibited by four of the six nerve agents displayed a linear relationship between $k_{\mathrm{obs}}$ and [MMB4]. Under these conditions, the association of MMB4 with the enzyme-OP conjugate may be the rate-limiting step in the reactivation reaction. If higher concentrations of MMB4 were used, saturation in the binding of MMB4 to the AChE-OP conjugate would be achieved. However, due to practical reasons, it was not possible to conduct reactivation studies with higher concentrations of MMB4.

Reactivation rate constants for GB- and GF-inhibited AChEs determined using purified enzymes in this study were comparable to those reported previously with erythrocyte ghosts (22). However, significantly higher second-order reactivation rate constants were observed for VX-inhibited GP and Hu AChEs in the previous study than those reported here. The reason for this discrepancy may be that reactivation kinetics were only measured over the first $10 \mathrm{~min}$ in the last study, while in the present study, the course of reactivation was measured for up to $2 \mathrm{~h}$. Since VX can form two AChE$\mathrm{VX}$ conjugates corresponding to the two enantiomers, which undergo oxime reactivation at different rates, the monitoring of reactivation for the first 10 min may mostly represent reactivation of the conjugate that reactivates faster. This discrepancy can be resolved by conducting reactivation studies with separate enzyme conjugates prepared from each of the two enantiomers of VX.

Differences in the rates of aging of nerve agent-inhibited GP and $\mathrm{rHu}$ AChEs were significantly less than those observed for oxime reactivation rates, with the most significant difference being 3-fold between GD-inhibited GP and $\mathrm{rHu}$ AChEs. Although the rate of aging was very low for GA-inhibited GP and rHu AChEs, these conjugates were much more difficult to reactivate compared with enzyme conjugates with other nerve agents. Only three of five tested 
oximes (2-PAM, MMB4, and HLo-7) were able to induce measurable reactivations of GA conjugate. The two other oximes (HI-6 and ICD-585) failed to reactivate either GP or $\mathrm{rHu} \mathrm{AChE}$ inhibited by GA, providing further proof for the resistance of enzyme-GA conjugate to oxime reactivation. The recent X-ray crystal structure of mouse AChEGA conjugate revealed that there was a repositioning of amino acid residues in GA-inhibited AChE compared with other enzyme conjugates (45). Also, the X-ray crystal structure of mouse AChE-HI-6 complex showed that the secondary pyridinium ring of HI-6 was sandwiched between W286 and Y124 of the peripheral anionic site (PAS) of AChE (10). These unique features may explain the unsuccessful reactivation of AChE-GA conjugates by HI-6 and ICD-585 observed in this study.

The most interesting observations were the pronounced differences in the reactivation of GF-, GD-, and VR-inhibited GP and rHu AChEs by HLo-7, HI-6, and ICD-585. In the 1980s, the H-series oximes HI-6 and HLo-7 were reported to be potent reactivators of AChE inhibited by GD, a nerve agent with a bulky pinacolyl side chain (46). Subsequent studies reported that these oximes were also potent reactivators of $\mathrm{AChE}$ inhibited by GF, another nerve agent with a bulky side chain (cyclohexyl) (28). The iso-butyryl side chain of VR is also relatively bulkier than other nerve agents such as VX and GB. Therefore, the high potencies of these three oximes in reactivating GF-, GD-, and VR-inhibited $\mathrm{rHu}$ AChE may stem from a unique interaction of these oximes with $\mathrm{Hu} \mathrm{AChE}$ to overcome the steric hindrance from these bulky side chains. Site-directed mutagenesis studies have indicated that reactivation by HI-6 and HLo-7 depends on the interaction of the second-pyridinium structure of oxime with the PAS of AChE $(32,47)$. It is possible that there may be differences in amino acid residues at the PAS of GP and $\mathrm{Hu} \mathrm{AChE}$ which may be responsible for species-related variations observed in oxime reactivation between these two enzymes. The determination of amino acid sequence for GP $\mathrm{AChE}$ and its comparison with $\mathrm{Hu} \mathrm{AChE}$ are necessary for explaining differences between these enzymes regarding oxime reactivation following nerve agent inhibition.

\section{ACKNOWLEDGMENT}

We thank Dr. Oksana Lockridge of the University of Nebraska Medical Center, for the kind gift of the plasmid containing the cDNA sequence encoding human AChE. The opinions or assertions contained herein are the private views of the authors and are not to be construed as official or as reflecting the views of the Army or the Department of Defense.

\section{REFERENCES}

1. MacIlwain, C. (1993) Study proves Iraq used nerve gas, Nature 363,3 .

2. Nagao, M., Takatori, T., Matsuda, Y., Nakajima, M., Iwase, H., and Iwadate, K. (1997) Definitive evidence for the acute sarin poisoning diagnosis in the Tokyo subway, Toxicol. Appl. Pharmacol. 144, 198-203.

3. Marrs, T. C. (1992): Clinical and Experimental Toxicology of Organophosphates and Carbamates, pp 555-577, Butterworth \& Heinemann, Oxford.

4. Gray, A. P. (1984) Design and structure-activity relationships of antidotes to organo-phosphorus anticholinesterase agents, Drug Metab. Rev. 15, 557-589.
5. de Jong, L. P., and Wolring, G. Z. (1980) Reactivation of acetylcholinesterase inhibited by $1,2,2^{\prime}$-trimethylpropyl methylphosphonofluoridate (soman) with HI-6 and related oximes, Biochem. Pharmacol. 29, 2379-2387.

6. Worek, F., Thiermann, H., Szinicz, L., and Eyer, P. (2004) Kinetic analysis of interactions between human acetylcholinesterase, structurally different organophosphorus compounds and oximes, Biochem. Pharmacol. 68, 2237-2248.

7. Lundy, P. M., Hansen, A. S., Hand, B. T., and Boulet, C. A. (1992) Comparison of several oximes against poisoning by soman, tabun and GF, Toxicology 72, 99-105.

8. Clement, J. G. (1982) HI-6: reactivation of central and peripheral acetylcholinesterase following inhibition by soman, sarin and tabun in vivo in the rat, Biochem. Pharmacol. 31, 1283-1287.

9. de Jong, L. P., Verhagen, M. A., Langenberg, J. P., Hagedorn, I., and Loffler, M. (1989) The bispyridinium-dioxime HLo-7. A potent reactivator for acetylcholinesterase inhibited by the stereoisomers of tabun and soman, Biochem. Pharmacol. 38, 633640 .

10. Ekstrom, F., Pang, Y. P., Boman, M., Artursson, E., Akfur, C., and Borjegren, S. (2006) Crystal structures of acetylcholinesterase in complex with HI-6, Ortho-7 and obidoxime: structural basis for differences in the ability to reactivate tabun conjugates, Biochem. Pharmacol. 72, 597-607.

11. Worek, F., Kirchner, T., Backer, M., and Szinicz, L. (1996) Reactivation by various oximes of human erythrocyte acetylcholinesterase inhibited by different organophosphorus compounds, Arch. Toxicol. 70, 497-503.

12. Luo, C., Leader, H., Radic, Z., Maxwell, D. M., Taylor, P., Doctor, B. P., and Saxena, A. (2003) Two possible orientations of HI-6 molecule in the reactivation of organophosphate-inhibited acetylcholinesterase, Biochem. Pharmacol. 66, 387-392.

13. Kuca, K., and Kassa, J. (2003) A comparison of the ability of a new bispyridinium oxime-1-(4-hydroxyiminomethylpyridinium)4-(4-carbamoylpyridinium)butane dibromide and currently used oximes to reactivate nerve agent-inhibited rat brain acetylcholinesterase by in vitro methods, J. Enzyme Inhib. Med. Chem. 18, 529-535.

14. Doctor, B. P., Raveh, L., Wolfe, A. D., Maxwell, D. M., and Ashani, Y. (1991) Enzymes as pretreatment drugs for organophosphate toxicity, Neurosci. Biobehav. Rev. 15, 123-128.

15. Li, W. F., Costa, L. G., and Furlong, C. E. (1993) Serum paraoxonase status: a major factor in determining resistance to organophosphates, J. Toxicol. Environ. Health 40, 337-346.

16. Maxwell, D. M., and Brecht, K. M. (1991) The role of carboxylesterase in species variation of oxime protection against soman Neurosci. Biobehav. Rev. 15, 135-139.

17. Oldiges, H., and Schoene, K. (1970) Pyridinium and imidazolium salts as antidotes for soman and paraoxon poisoning in mice, Arch Toxicol. 26, 293-305.

18. Schoene, K., and Oldiges, H. (1973) Efficacy of pyridinium salts in tabun and sarin poisoning in vivo and in vitro, Arch Int. Pharmacodyn. Ther. 204, 110-123.

19. Schoene, K. (1980) Pyridinium salts as organophosphate antagonists, Monogr. Neural Sci. 7, 85-98.

20. Worek, F., and Szinicz, L. (1995) Cardiorespiratory function in nerve agent poisoned and oxime + atropine treated guinea-pigs: effect of pyridostigmine pretreatment, Arch. Toxicol. 69, 322329.

21. Lundy, P. M., Goulet, J. C., and Hand, B. T. (1989) Hormoneand dose schedule-dependent protection by HI-6 against soman and tabun poisoning, Fundam. Appl. Toxicol. 12, 595-603.

22. Worek, F., Reiter, G., Eyer, P., and Szinicz, L. (2002) Reactivation kinetics of acetylcholinesterase from different species inhibited by highly toxic organophosphates, Arch. Toxicol. 76, 523-529.

23. Low, M. G., and Finean, J. B. (1997) Non-lytic release of acetylcholinesterase from erythrocytes by a phosphatidylinositolspecific phospholipase C, FEBS Lett. 82, 143-146.

24. Ralston, J. S., Rush, R. S., Doctor, B. P., and Wolfe, A. D. (1985) Acetylcholinesterase from fetal bovine serum. Purification and characterization of soluble G4 enzyme, J. Biol. Chem. 260, 43124318.

25. Luo, C., Saxena, A., Smith, M., Garcia, G., Radic, Z., Taylor, P., and Doctor, B. P. (1999) Phosphoryl oxime inhibition of acetylcholinesterase during oxime reactivation is prevented by edrophonium, Biochemistry 38, 9937-9947.

26. Ellman, G. L., Courtney, K. D., Andres, V., and Featherstone, R. M. (1961) A new and rapid colorimetric determination of acetylcholinesterase activity, Biochem. Pharmacol. 7, 88-95. 
27. Wong, L., Radic, Z., Bruggemann, R. J. M., Hosea, N., Berman, H., and Taylor, P. (2000) Mechanism of oxime reactivation of acetylcholinesterase analyzed by chirality and mutagenesis, Biochemistry 39, 5750-5757.

28. Worek, F., Eyer, P., and Szinicz, L. (1998) Inhibition, reactivation and aging kinetics of cyclohexylmethylphosphonofluoridateinhibited human cholinesterases, Arch. Toxicol. 72, 580-587.

29. Gray, A. P., Platz, R. D., Henderson, T. R., Chang, T. C., Takahashi, K., and Dretchen, K. L. (1988) Approaches to protection against nerve agent poisoning. (Naphthylvinyl)pyridine derivatives as potential antidotes, J. Med. Chem. 31, 807-814.

30. Ordentlich, A., Barak, D., Sod-Moriah, G., Kaplan, D., Mizrahi, D., Segall, Y., Kronman, C., Karton, Y., Lazar, A., Marcus, D., Velan, B., and Shafferman, A. (2004) Stereoselectivity toward VX is determined by interactions with residues of the acyl pocket as well as of the peripheral anionic site of AChE, Biochemistry 43, 11255-11265.

31. Boter, H. L., and van Dijk, C. (1969) Stereospecificity of hydrolytic enzymes on reaction with asymmetric organophosphorus compounds. 3. The inhibition of acetylcholinesterase and butyrylcholinesterase by enantiomeric forms of sarin, Biochem. Pharmacol. 18, 2403-2407.

32. Benschop, H. P., Konings, C. A., Van Genderen, J., and de Jong, L. P. (1984) Isolation, anticholinesterase properties, and acute toxicity in mice of the four stereoisomers of the nerve agent soman, Toxicol. Appl. Pharmacol. 72, 61-74.

33. Ashani, Y., Radic, Z., Tsigelny, I., Vellom, D. C., Pickerring, N. A., Quinn, D. M., Doctor, B. P., and Taylor, P. (1995) Amino acid residues controlling reactivation of organo-phosphonyl conjugates of acetylcholinesterase by mono- and bisquaternary oximes, J. Biol. Chem. 270, 6370-6380.

34. Quinn, D. M. (1987) Acetylcholinesterase: enzyme structure, reaction dynamics and virtual transition states, Chem. Rev. 87, 955-979.

35. Saxena, A., Qian, N., Kovach, I. M., Kozikowski, A. P., Pang, Y. P., Vellom, D. C., Radic, Z., Quinn, D., Taylor, P., and Doctor, B. P. (1994) Identification of amino acid residues involved in the binding of Huperzine A to cholinesterases, Protein Sci. 3, 17701778.

36. Qadri, Y. H., Swamy, A. N., and Rao, J. V. (1994) Species differences in brain acetylcholinesterase response to monocrotophos in vitro, Ecotoxicol. Environ. Safety 28, 91-98.
37. Kemp, J. R., and Wallace, K. B. (1990) Molecular determinants of the species-selective inhibition of brain acetylcholinesterase, Toxicol. Appl. Pharmacol. 104, 246-258.

38. Marcel, V., Estrada-Mondaca, S., Magne, F., Stojan, J., Klaebe, A., and Fournie, D. (2000) Exploration of the Drosophila acetylcholinesterase substrate activation site using a reversible inhibitor (Triton X-100) and mutated enzymes, J. Biol. Chem. 275, 11603-11609.

39. Fournier, D. (2005) Mutations of acetylcholinesterase which confer insecticide resistance in insect populations, Chem.-Biol. Interact. 157-158, 257-261.

40. Wallace, K. B., and Herzberg, U. (1988) Reactivation and aging of phosphorylated brain acetylcholinesterase from fish and rodents, Toxicol. Appl. Pharmacol. 92, 307-314.

41. de Jong, L. P., and Wolring, G. Z. (1985) Aging and stereospecific reactivation of mouse erythrocyte and brain acetylcholinesterases inhibited by soman, Biochem. Pharmacol. 34, 142-145.

42. Boskovic, B., Maksimovic, M., and Minic, D. (1968) Ageing and reactivation of acetylcholinesterase inhibited with soman and its thiocholine-like analogue, Biochem. Pharmacol. 17, 1738-1741.

43. de Jong, L. P., and Wolring, G. Z. (1984) Stereospecific reactivation by some Hagedorn-oximes of acetylcholinesterases from various species including man, inhibited by soman, Biochem. Pharmacol. 33, 1119-1125.

44. Aurbek, N., Thiermann, H., Szinicz, L., Eyer, P., and Worek, F. (2006) Analysis of inhibition, reactivation and aging kinetics of highly toxic organophosphorus compounds with human and pig acetylcholinesterase, Toxicology 224, 91-99.

45. Ekstrom, F., Akfur, C., Tunemalm, A. K., and Lundberg, S. (2006) Structural changes of phenylalanine 338 and histidine 447 revealed by the crystal structures of tabun-inhibited murine acetylcholinesterase, Biochemistry 45, 74-81.

46. de Jong, L. P. A., Verhagen, M. A. A., Langenberg, J. P., and Hagedorn, I. (1989) The bispyridinium-di-oxime HLo-7: A potent reactivator for acetylcholinesterase inhibited by the stereoisomers of tabun and soman, Biochem. Pharmacol. 38, 633-640.

47. Luo, C., Chambers, C., Tong, M., Tipparaju, P., Doctor, B. P., and Saxena, A. (2006) Development of broad-spectrum oxime for the treatment of nerve agent toxicity, Proceedings of 25th Army Science Conference, Nov 27-Dec 1, 2006, Orlando, FL. 